\title{
Relating tinnitus features and audiometric characteristics in a cohort of 34 tinnitus subjects
}

\author{
María Cuesta, Pedro Cobo \\ Institute of Physical and Information Technologies (ITEFI), CSIC, Serrano 144, 28006 Madrid, Spain \\ m.cuesta@csic.es ORCID: http://orcid.org/0000-0002-7729-8568 \\ pedro.cobo@csic.es ORCID: http://orcid.org/0000-0002-3406-1122
}

Submitted: 08/11/2017. Accepted 03/05/2018. Publicado online: 10/01/2019

Citation / Cómo citar este artículo: María Cuesta and Pedro Cobo. (2018). Relating tinnitus features and audiometric characteristics in a cohort of 34 tinnitus subjects. Loquens, 5(2), e054. https://doi.org/10.3989/1oquens.2018.054

\begin{abstract}
Although tinnitus, the conscious perception of a sound without a sound source external or internal to the body, is highly correlated with hearing loss, the precise nature of such correlation remains still unknown. People with high pitch tinnitus are used to suffer from high frequency hearing losses, and vice versa, low pitch tinnitus is mostly associated with low frequency hearing losses. However, many subjects with low or high frequency losses do no develop tinnitus. Thus, studies trying to relate audiometric characteristics and tinnitus features are still relevant. This article presents a correlational study of audiometric and tinnitus variables in a sample of 34 subjects, paying special attention to the heterogeneous subtypes of both audiometry shape and tinnitus etiology. Our results, which concur with others previously published, demonstrate that the tinnitus pitch, the main frequency of the tinnitus spectrum, in subjects with high-steep high-frequency and continuously steep hearing losses, are highly correlated with the frequency at which hearing loss reaches $50 \mathrm{~dB} \mathrm{HL}$.
\end{abstract}

Keywords: hearing loss; tinnitus; audiometry; tinnitus pitch.

RESUMEN: Relación entre las características audiométricas y acufenométricas en un grupo de 34 pacientes de acúfeno.- Aunque el acúfeno, la percepción consciente de un sonido en ausencia de una fuente externa o interna, está altamente correlacionada con las pérdidas auditivas, aún no se conoce la naturaleza precisa de esta relación. Las personas con acúfeno de alta frecuencia suelen tener pérdidas auditivas de alta frecuencia, y viceversa, cuando el acúfeno percibido es de baja frecuencia, las pérdidas auditivas también afectan a la parte de baja frecuencia del espectro auditivo. Sin embargo, hay muchas personas que sufren de pérdida de audición y sin embargo no desarrollan el acúfeno. Por consiguiente, aún son pertinentes los estudios que tratan de relacionar características audiométricas y acufenómetricas en una misma muestra de sujetos. Este artículo presenta los resultados de un estudio correlacional en una muestra de 34 participantes, prestando especial atención a los distintos y heterogéneos subtipos tanto de audiometría como de etiología del acúfeno. Nuestros resultados, que están de acuerdo con otros publicados previamente, demuestran que la frecuencia del acúfeno, en los subtipos de audiometría con una pendiente alta en alta frecuencia y en estos con una pendiente continuamente decreciente, está altamente correlacionada con la frecuencia a la cual la pérdida de audición alcanza los $50 \mathrm{~dB}$ HL.

Palabras clave: pérdida auditiva; acúfeno; audiometría; frecuencia del acúfeno.

\section{INTRODUCTION}

Tinnitus is the conscious perception of sound heard in the absence of physical sound sources external or internal to the body (Eggermont \& Tass, 2015). Epidemiological studies report that tinnitus roughly affects $10 \%$ of the adult population (Hall et al., 2015) and severely disturbs the quality of life of about $1-2 \%$ of adults by producing anxiety, annoyance, irritability, disturbed sleep patterns, and depression (Cobo, 2015; Diges, Simón, \& Cobo, 2017; Van de Heyning et al., 2007; Vio \& Holme, 2005). 
Similar to in phantom limb pain, tinnitus perception seems to be the correlate of maladaptive attempts of the brain at reorganization due to deprived sensory input. Therefore, hearing loss (HL) is the most important risk factor for developing tinnitus (Kleinjung, Steffens, Struz, \& Langguth, 2009). The central auditory system compensates for diminished input by upregulating its responsiveness in central circuitries. Central compensation that follows reduced auditory nerve activity may occur first at the level of the auditory brainstem, from where altered activity patterns then spread to ascending auditory nuclei. Electrophysiological and functional imaging measurements in humans and animals suggest the following neural correlates of tinnitus in the auditory system (Eggermont, 2012):

- Increased neural synchrony (hypersynchrony)

- Increased spontaneous firing rates (hyperactivity)

- Reorganization of tonotopic map

Tinnitus can occur at both sub-cortical and/or cortical levels, suggesting two different tinnitus subtypes: cochlear and central (Noreña, 2011; Milloy, Fournier, Benoit, Noreña, \& Koravand, 2017). Cochlear tinnitus results from a hyperactivity at the acoustic nerve and is the subtype taking place in salicylate induced tinnitus in animal models. Central tinnitus, on the other hand, outcomes due to cortical changes (mainly hypersynchrony and tonotopic map reorganization) due to HL, and is the subtype happening in noise induced tinnitus in animal models (Noreña, 2011).

Tinnitus and HL are highly correlated. According to Eggermont (2014), the prevalence of tinnitus is a cubic-root function of the prevalence of significant HL ( $\mathrm{HL}>25 \mathrm{~dB}$ from $500 \mathrm{~Hz}$ to $4 \mathrm{kHz}$ ). However, although chronic tinnitus is often accompanied by some kind of hearing deficit, it is still unknown how HL can actually produce tinnitus, as many HL impaired people do not develop tinnitus. The intriguing relationship between tinnitus and HL is even more disconcerting as $25 \%$ of tinnitus participants in a research study had normal hearing up to $8 \mathrm{kHz}$ (Roberts, Moffat, \& Bosnyak, 2006).

Many researchers have investigated how the tinnitus occurrence and the HL curve (the audiogram) shape are related (König, Schaette, Kempter, \& Gross, 2006; Langguth et al., 2017; Schecklmann et al., 2012; Sereda et al., 2011; Shekhawat, Searchfield, \& Stinea, 2014). For example, the perceived frequency of tinnitus, also called the tinnitus pitch (TP in the following), is usually associated with frequencies showing HL, i.e., high pitch tinnitus is associated to high frequencies HL, and low pitch tinnitus with low frequencies HL (Shekhawat et al., 2014).

Different theories have been proposed to relate different types of HL with TP (Schecklmann et al., 2012). Roberts, Bosnyak, Bruce, Gander, and Paul (2015), based in similarity judgments, reported that tinnitus subjects matched their TP near the edge frequency of the audiogram, that is, the frequency at which the HL commences. Thus, one theory proposes the edge frequency as the mechanism triggering the tinnitus by a lateral inhibition imbalance, which results in an over representation of this edge frequency at cortical level (reorganization of the tonotopic map). According to this theory, the TP should correspond to the edge frequency of the HL.

Shekhawat et al. (2014) proposed the frequency associated to dead region as the most likely audiometric characteristic related to TP. Previously, Weisz, Hartmann, Dohrmann, Schlee, and Noreña (2006) demonstrated that $72.7 \%$ of tinnitus sufferers had dead regions. The dead region is the cochlea zone where the inner ear cells (IHC) are not functioning. In fact, IHC damage has been identified as a prerequisite for auditory pathway deafferentation and tonotopic reorganization. Post mortem studies have demonstrated that IHC damage starts roughly at $\mathrm{HL}=50 \mathrm{~dB}$ (Shekhawat et al., 2014). Therefore, the frequency at which HL $=50 \mathrm{~dB}$ (F50 in the following) was proposed by Shekhawat et al. (2014) as the most probable audiometric correlate of TP. Other possible audiometric correlates of TP were analyzed by Shekhawat et al. (2014), namely, the frequency at which HL approximately begins, that is the frequency for $\mathrm{HL}=20 \mathrm{~dB}$ (F20 in the following), and the frequency at which HL is maximum (Fmax in the following). Notice that F20 could be assimilated to the edge frequency proposed by Roberts et al. (2015).

Alternatively, Schecklmann et al. (2012) suggested that tinnitus is caused by homeostatic plasticity, which compensates for deprived sensory input by increasing spontaneous firing rate and neural synchrony in the corresponding auditory pathway. According to this theory, the TP should correspond to the frequency for maximum HL, that is, Fmax.

Therefore, studies of relationship between audiometric characteristics, obtained from the HL curve shape, and tinnitus features, mainly the TP, are still relevant. Hence, the aim of this article is to provide the results of such a study in a cohort of 34 tinnitus volunteers, which undertook joint audiometric and tinnitus measurements in our laboratory. When analyzing the relationship between tinnitus features and audiometric characteristics, the following issues should be taken into consideration:

1. The procedure to assess the tinnitus features, for instance, the tinnitus pitch.

2. The way the audiometric characteristics are obtained, namely, which attributes from the HL are used and how they are measured.

3. The statistical methods used for testing tinnitus features and audiometric characteristics.

\section{MATERIAL AND METHODS}

\subsection{Participants}

The study was approved by the Research Bioethics Subcommittee of the Spanish National Research Council (CSIC) and was conducted in accordance with the Spanish 
Law of Data Protection (RD1720/2007). 34 volunteers with tinnitus ( 21 men, age $51 \pm 14$ years, 13 women, age $45 \pm 11$ years) were recruited through Spanish Tinnitus Associations and Tinnitus Clinics. Subjects with audiological surgical history (otosclerosis, tumors, head trauma...) were excluded. All participants in this study gave their written informed consent.

Columns 1-3 of Table 1 show the assigned number, sex and age, respectively, of each participant.

\subsection{Audiometric measurements}

Each subject underwent HL measurements by puretone audiometry of both ears. HL curves were measured with the Clinic Audiometer GSI 60, using pure tones at 11 pre-specified frequencies $(125,250,500750,1000$, $1500,2000,3000,4000,6000$, and $8000 \mathrm{~Hz}) .32$ of 35 subjects have HL similar for left and right ears. On the other hand, 3 of $35\left(18,21\right.$, and 25) have $\mathrm{HL}_{\text {left ear }}$ and

Table 1: Audiometric characteristics of participants.

\begin{tabular}{|c|c|c|c|c|c|c|c|c|c|}
\hline Subject & Sex & Age & $\begin{array}{c}\text { HL subtype } \\
\left(^{*}\right)\end{array}$ & $\frac{\text { F20 }_{\text {left ear }}}{(\mathrm{Hz})}$ & $\begin{array}{c}\text { F20 }_{\text {right ear }} \\
(\mathrm{Hz})\end{array}$ & $\begin{array}{c}\text { F50 } \text { left ear }_{\text {en }} \\
(\mathrm{Hz})\end{array}$ & $\begin{array}{c}\text { F50 } \text { right ear }_{\text {r }} \\
(\mathrm{Hz})\end{array}$ & $\frac{\text { Fmax }_{\text {left ear }}}{(\mathbf{H z})}$ & $\frac{\text { Fmax }_{\text {right ear }}}{(\mathbf{H z})}$ \\
\hline 1 & $\mathrm{~F}$ & 45 & $\mathrm{~F}$ & $\mathrm{n} / \mathrm{a}$ & $\mathrm{n} / \mathrm{a}$ & $\mathrm{n} / \mathrm{a}$ & $\mathrm{n} / \mathrm{a}$ & 125 & 125 \\
\hline 2 & M & 63 & HS & 1498 & 1928 & 2599 & 1499 & 8000 & 8000 \\
\hline 3 & M & 39 & $\mathrm{~F}$ & 499 & 748 & $\mathrm{n} / \mathrm{a}$ & $\mathrm{n} / \mathrm{a}$ & 1500 & 750 \\
\hline 4 & M & 44 & HS & 4665 & 4996 & 5998 & 9000 & 6000 & 8000 \\
\hline 5 & M & 53 & HS & 2498 & 2496 & 3998 & 7980 & 8000 & 8000 \\
\hline 6 & M & 50 & HS & 3496 & 998 & 7712 & 9000 & 8000 & 8000 \\
\hline 7 & M & 43 & HS & 3664 & 6796 & 9000 & 9000 & 8000 & 8000 \\
\hline 8 & $\mathrm{~F}$ & 50 & HS & 6661 & 249 & 9000 & 9000 & 8000 & 8000 \\
\hline 9 & $\mathrm{~F}$ & 41 & $\mathrm{CS}$ & 167 & 208 & 500 & 749 & 6000 & 8000 \\
\hline 10 & $\mathrm{~F}$ & 67 & HS & 249 & 4496 & 9000 & 9000 & 6000 & 8000 \\
\hline 11 & M & 28 & $\mathrm{~F}$ & $\mathrm{n} / \mathrm{a}$ & $\mathrm{n} / \mathrm{a}$ & $\mathrm{n} / \mathrm{a}$ & $\mathrm{n} / \mathrm{a}$ & 6000 & 6000 \\
\hline 13 & $\mathrm{~F}$ & 45 & $\mathrm{CS}$ & 125 & 125 & 9000 & 2995 & 750 & 8000 \\
\hline 14 & M & 62 & HS & 417 & 437 & 3363 & 2666 & 6000 & 6000 \\
\hline 15 & M & 31 & $\mathrm{ST}$ & 1083 & 750 & 1624 & 1278 & 2000 & 2000 \\
\hline 16 & M & 68 & $\mathrm{CS}$ & 499 & 624 & 5997 & 7996 & 8000 & 8000 \\
\hline 17 & $\mathrm{~F}$ & 47 & HS & 1498 & 4748 & 5330 & 6000 & 6000 & 6000 \\
\hline 18 & M & 65 & HS & 125 & 1498 & 999 & 9000 & 8000 & 8000 \\
\hline 19 & $\mathrm{~F}$ & 61 & $\mathrm{~F}$ & 749 & 5991 & $\mathrm{n} / \mathrm{a}$ & $\mathrm{n} / \mathrm{a}$ & 1000 & 8000 \\
\hline 20 & M & 41 & $\mathrm{~F}$ & 6991 & $\mathrm{n} / \mathrm{a}$ & $\mathrm{n} / \mathrm{a}$ & $\mathrm{n} / \mathrm{a}$ & 8000 & 125 \\
\hline 21 & M & 47 & ST & 2398 & 2332 & 3500 & 3249 & 3000 & 4000 \\
\hline 22 & $\mathrm{~F}$ & 45 & $\mathrm{CS}$ & 156 & 125 & 2798 & 3495 & 4000 & 6000 \\
\hline 23 & M & 42 & $\mathrm{~F}$ & 2498 & 2996 & $\mathrm{n} / \mathrm{a}$ & $\mathrm{n} / \mathrm{a}$ & 3000 & 3000 \\
\hline 24 & M & 37 & $\mathrm{~F}$ & 3998 & 7981 & $\mathrm{n} / \mathrm{a}$ & $\mathrm{n} / \mathrm{a}$ & 6000 & 8000 \\
\hline 25 & M & 69 & HS & 498 & 249 & 1999 & 7197 & 6000 & 8000 \\
\hline 26 & $\mathrm{M}$ & 44 & $\mathrm{~F}$ & 5991 & $\mathrm{n} / \mathrm{a}$ & $\mathrm{n} / \mathrm{a}$ & $\mathrm{n} / \mathrm{a}$ & 6000 & 6000 \\
\hline 27 & $\mathrm{~F}$ & 26 & $\mathrm{~F}$ & $\mathrm{n} / \mathrm{a}$ & $\mathrm{n} / \mathrm{a}$ & $\mathrm{n} / \mathrm{a}$ & $\mathrm{n} / \mathrm{a}$ & 6000 & 8000 \\
\hline 28 & $\mathrm{~F}$ & 29 & ST & 3997 & 3331 & 5000 & 5000 & 6000 & 4000 \\
\hline 29 & $\mathrm{M}$ & 58 & HS & 1996 & 2331 & 5327 & 6796 & 8000 & 8000 \\
\hline 30 & $\mathrm{~F}$ & 42 & $\mathrm{~F}$ & 333 & $\mathrm{n} / \mathrm{a}$ & $\mathrm{n} / \mathrm{a}$ & $\mathrm{n} / \mathrm{a}$ & 6000 & 125 \\
\hline 31 & $\mathrm{~F}$ & 41 & $\mathrm{~F}$ & 5994 & $\mathrm{n} / \mathrm{a}$ & $\mathrm{n} / \mathrm{a}$ & $\mathrm{n} / \mathrm{a}$ & 6000 & 8000 \\
\hline 32 & M & 36 & HS & 2499 & 2428 & 4990 & 6000 & 6000 & 6000 \\
\hline 33 & M & 75 & HS & 125 & 125 & 1374 & 2444 & 6000 & 8000 \\
\hline 34 & $\mathrm{~F}$ & 50 & HS & 2331 & 1998 & 7994 & 5994 & 8000 & 6000 \\
\hline
\end{tabular}

(*) F=Flat, HS=High-steep high-frequency, CS=Continuously steep, $\mathrm{ST}=$ Scotoma 
Figure 1: Mean HL (superimposed to individual HL) for flat HL subtype and (a) right ear, (b) left ear.
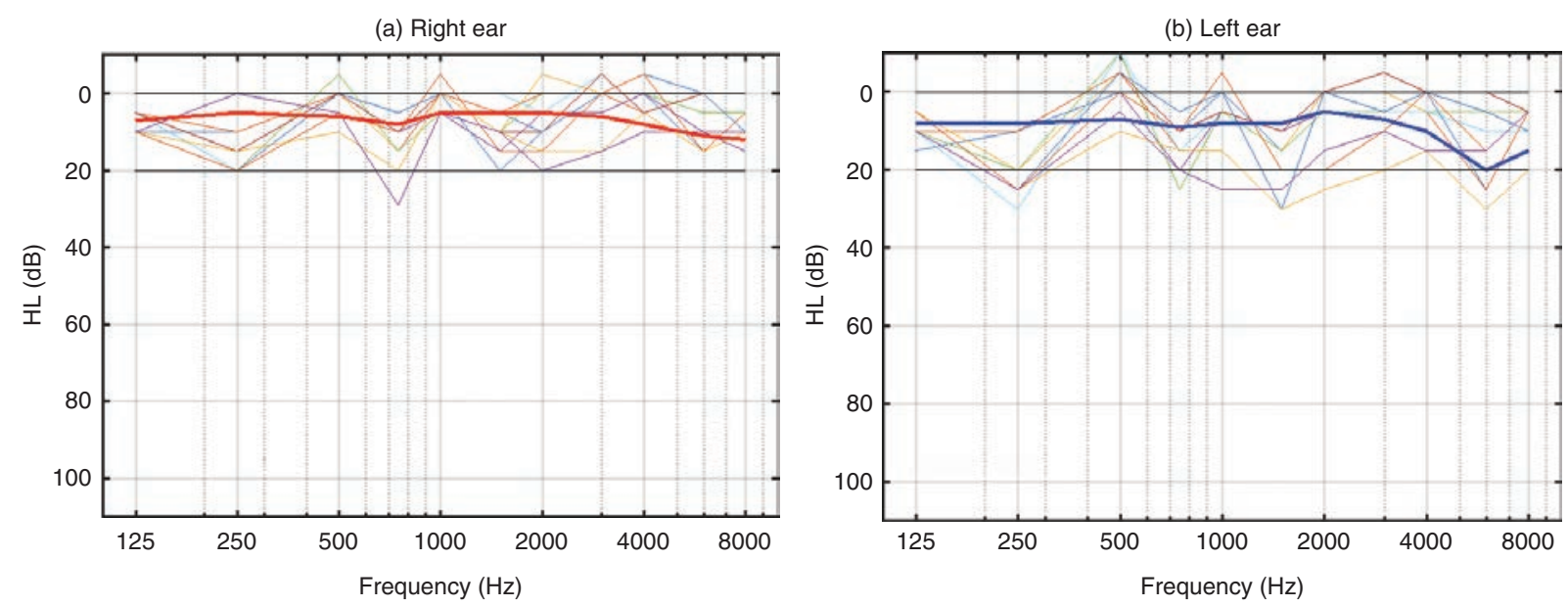

Figure 2: Mean HL (superimposed to individual HL) for high-steep high-frequency HL subtype and (a) right ear, (b) left ear.

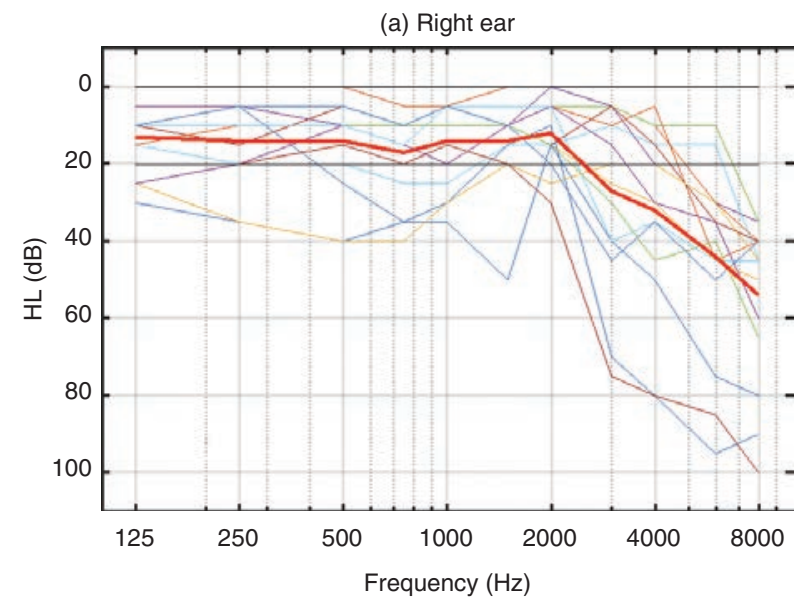

$\mathrm{HL}_{\text {right ear }}$ significantly different. Looking at the HL curves of participants, four subtypes can be defined:

1. Roughly flat HL (Figure 1; participants 1, 3, 11, 19, 20, 23, 24, 26, 27, 30, and 31).

2. High-steep high-frequency HL (Figure 2) (participants 2, 4, 5, 6, 7, 8, 10, 14 17, 18 (left ear), 25 (more in left ear), (29, 32, 33, and 34).

3. Continuously steep HL (Figure 3; participants 9, $12,13,16$, and 22).

4. HL with a scotoma (Figure 4; participants 15, 21, and 28).

Figures 1-4 depict mean HL curves (superimposed to individual HL) for these four subtypes. Column 4 of Table 1 shows the HL subtype of each participant.

\subsection{Audiometric characteristics}

The frequencies at which HL attains $20 \mathrm{~dB}, \mathrm{~F} 20,50 \mathrm{~dB}$, F50, and its maximum, Fmax, for left and right ears, are summarized in Table 2. To improve the estimation of F20

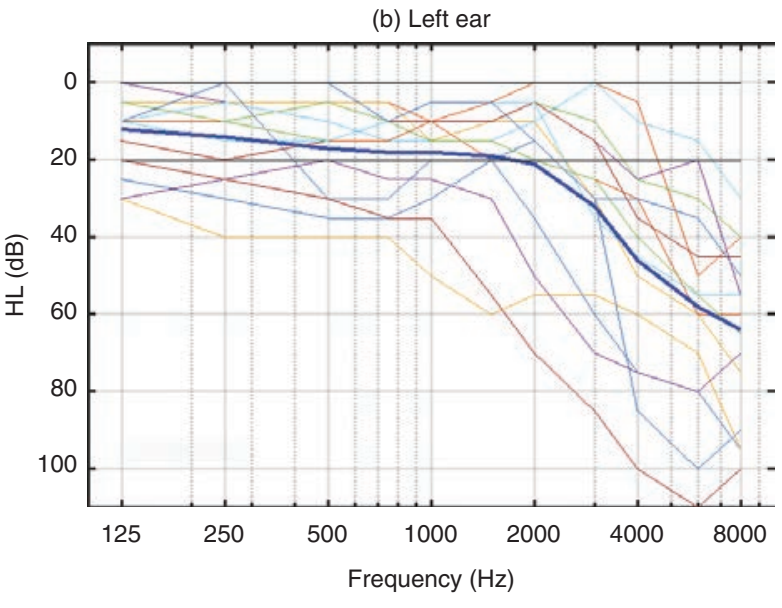

and F50, finer HLs are linearly interpolated first from measured HLs. This interpolation improves the estimation of the cutting of HL curves with $\mathrm{HL}=20$ and $\mathrm{HL}=50$. However, despite this interpolation, it was not possible to find F20 and F50 for some cases (mainly for flat HL subtypes), as HL curves do not reach these values. In these cases, $\mathrm{n} / \mathrm{a}$ is used for the corresponding F20 and F50 values. The HL curves of some participants deserve special consideration. Firstly, HLs are greater than $20 \mathrm{~dB}$ for subject 13 , in both ears, and for subject 18 , in left ear. In these cases, we assign arbitrarily F20 $=125 \mathrm{~Hz}$. Secondly, $\mathrm{HL}<50$ in subjects $6,7,8,10,13,18,21,28$, and 32 . In these subjects, F50 are assigned to the closer frequency at which $\mathrm{HL}=40$ or $45 \mathrm{~dB}$.

\subsection{Tinnitus features}

The tinnitus characteristics were assessed on the basis of the responses of the participants to the clinical evaluation sheet. The interview to participants included temporal (variability), spectral (pitch), and spatial (location) aspects of their tinnitus. Furthermore, additional information of 
Figure 3: Mean HL (superimposed to individual HL) for continuously steep HL subtype and (a) right ear, (b) left ear.

(a) Righ tear

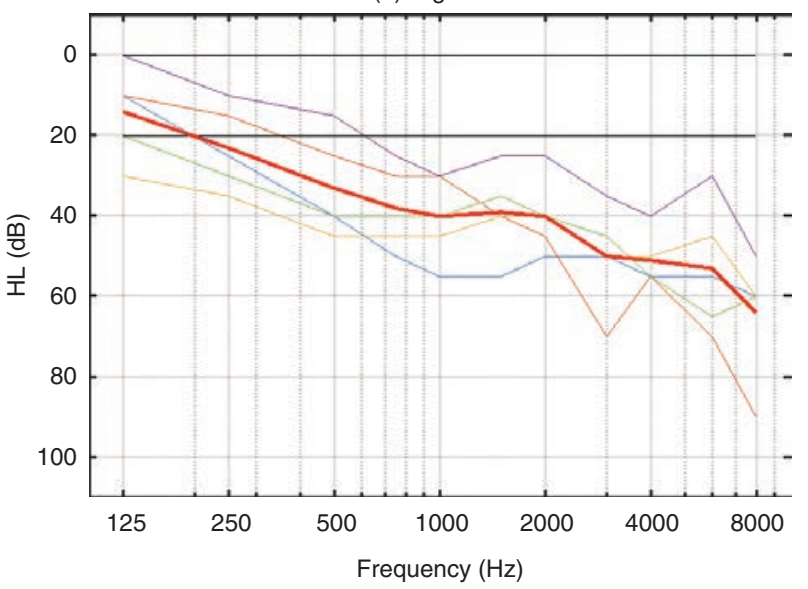

(b) Left ear

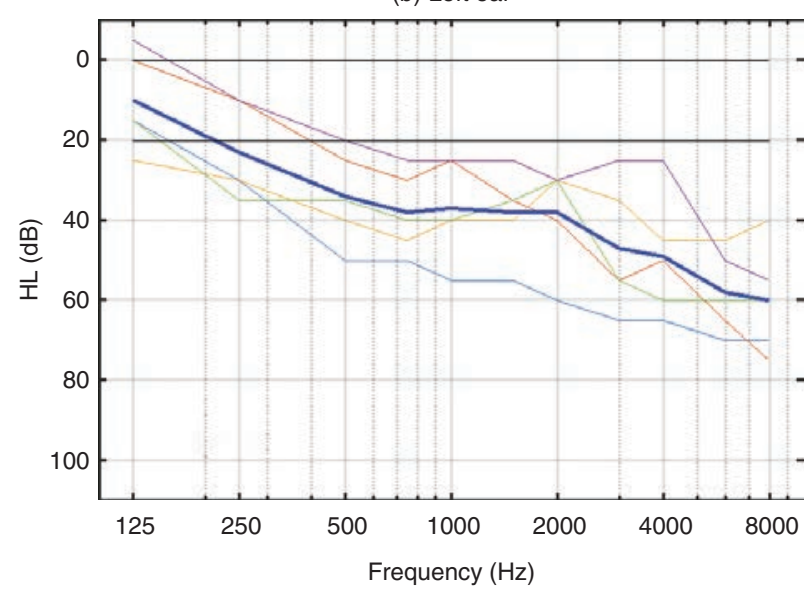

Figure 4: Mean HL (superimposed to individual HL) for HL with scotoma subtype and (a) right ear, (b) left ear.

(a) Right ear

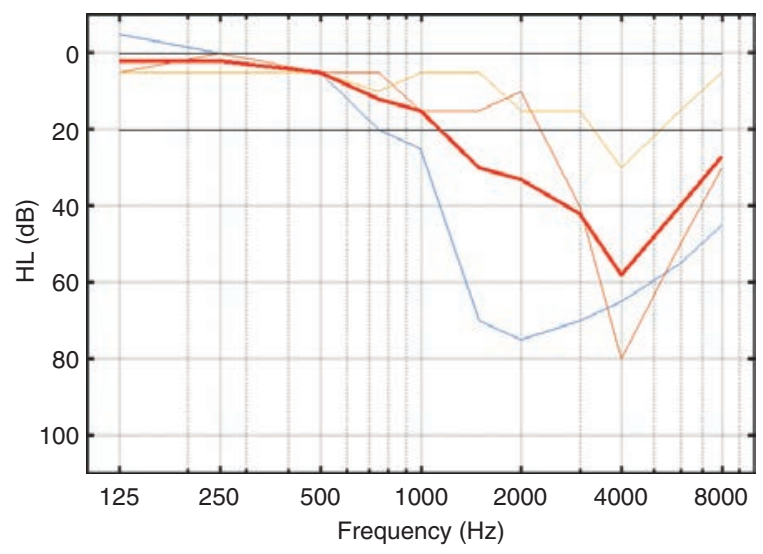

participants was obtained, including anamnesis (clinic history), tinnitus severity through Visual Analog Scale (VAS) and a Spanish version of the Tinnitus Handicap Inventory (THI; Herráiz, Hernández Calvín, Plaza, Tapia, $\&$ de los Santos, 2001). The anamnesis included information about the history and descriptive characteristics of the tinnitus, their possible etiology, previous tinnitus treatments, and relevant comorbidities.

The type and pitch of the tinnitus were evaluated using the self designed Graphical User Interface (GUI) of Figure 5. Using this GUI, tones, ringing and hissing sounds can be easily generated. This is accomplished by creating a band-pass filtered noise. Two parameters (central frequency and bandwidth) determine the type of sound. The bandwidth is defined as a percentage of the central frequency. For instance, for tones the band-pass is very narrow $(0.1 \%)$. Ringing are narrowband noises (bandwidth lesser than 10\%) while hissing are wideband noises (bandwidth greater than 10\%).

For tinnitus pitch matching, participants were sat in front of the computer where the GUI runs. Firstly, they (b) Left ear

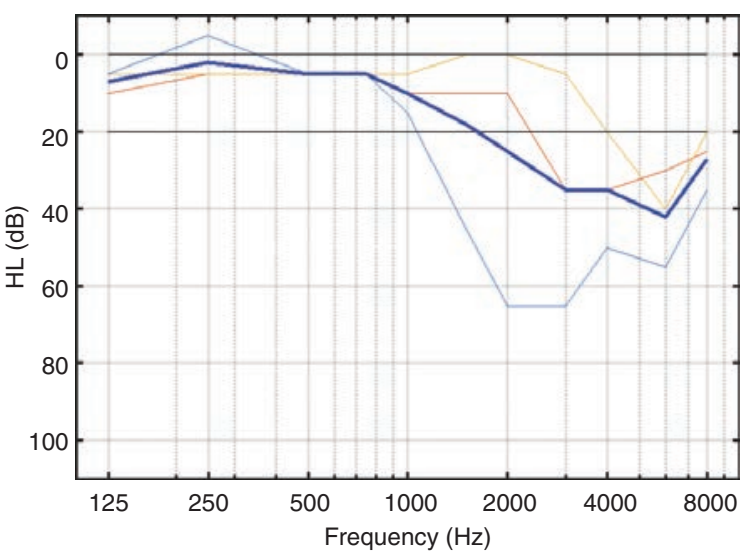

are trained in how tones, ringing, and hissing sound. Then, they are asked to identify roughly which sound is more similar to their tinnitus. After that, subjects are trained on the effect of central frequency and bandwidth on the sounds. Finally, a bracketing procedure is used to match as close as possible the sound generated by the GUI to its own tinnitus. It must be mentioned that some participants referred several types of sounds. In this case, the GUI is run consecutively to match all the sounds perceived by the participant.

Table 3 summarizes the resulting tinnitus characteristics of participants. Tinnitus is located either to left ear, right ear, bilateral (both ears), or the centre head. Some participants hear different types of tinnitus in each ear. A variety of etiologies were identified by the subjects, including sensorineural HL, conductive HL (otitis, Eustachian tube dysfunction), stress, noise, head trauma, and sinusitis. Some of the participants referred several possible origins of their tinnitus. When a tinnitus trigger is not clearly identified, the etiology is referred as idiopathic. 


\subsection{Data analysis}

Numerical proportions of different types of HL and tinnitus are appraised first by pie charts. Then, scatter plots and Spearman rank correlation analysis are applied

Table 2: Comparison of F20, F50, Fmax, and TP for the different HL subtypes.

\begin{tabular}{|c|c|c|c|c|c|}
\hline $\begin{array}{c}\text { HL } \\
\text { subtype }\end{array}$ & Subject & $\begin{array}{l}F 20 \\
(\mathrm{~Hz})\end{array}$ & $\begin{array}{l}\mathrm{F50} \\
(\mathrm{Hz})\end{array}$ & $\begin{array}{c}\text { Fmax } \\
(H z)\end{array}$ & $\begin{array}{c}T P \\
(H z)\end{array}$ \\
\hline \multirow{15}{*}{ HS } & 2 & 1748 & 2049 & 8000 & 5000 \\
\hline & 4 & 4830 & 7500 & 7000 & 4500 \\
\hline & 5 & 2498 & 3998 & 8000 & 4400 \\
\hline & 6 & 3496 & 712 & 8000 & 12500 \\
\hline & 7 & 3664 & 9000 & 8000 & 7000 \\
\hline & 8 & 3455 & 9000 & 8000 & 8000 \\
\hline & 10 & 249 & 9000 & 6000 & 5000 \\
\hline & 14 & 437 & 2666 & 6000 & 3100 \\
\hline & 17 & 1498 & 5330 & 6000 & 5200 \\
\hline & 18 & 811 & 5000 & 8000 & 3900 \\
\hline & 25 & 498 & 1999 & 6000 & 3500 \\
\hline & 29 & 1996 & 5327 & 8000 & 5500 \\
\hline & 32 & 2499 & 4990 & 6000 & 3100 \\
\hline & 33 & 125 & 1909 & 7000 & 3500 \\
\hline & 34 & 2165 & 6994 & 7000 & 7500 \\
\hline \multirow{5}{*}{ CS } & 9 & 167 & 500 & 6000 & 3000 \\
\hline & 12 & 416 & 2664 & 8000 & 4000 \\
\hline & 13 & 125 & 5997 & 750 & 3800 \\
\hline & 16 & 561 & 6998 & 8000 & 8300 \\
\hline & 22 & 145 & 3145 & 5000 & 2000 \\
\hline \multirow{3}{*}{ ST } & 15 & 917 & 1451 & 2000 & 2400 \\
\hline & 21 & 2332 & 3249 & 3000 & 12000 \\
\hline & 28 & 3664 & 5000 & 5000 & 3000 \\
\hline
\end{tabular}

to paired tinnitus and audiological variables. Spearman rank correlation is used to identify and test the strength of relationships between these variables (Diges, Simón, \& Cobo, 2017). Positive Spearman correlation coefficients $(\rho)$ between $x$ and $y$ variables denote that both variables increase monotonically, and vice versa, a negative correlation coefficient indicates that when $x$ increases $y$ decreases monotonically. The correlation between the variables is considered to be very weak for $|\rho| \leq 0.2$, weak for $0.2<|\rho| \leq 0.4$, moderate for $0.4<|\rho| \leq 0.6$, strong for $0.6<|\rho| \leq 0.8$, and very strong for $|\rho|>0.8$.

\section{RESULTS}

Numerical proportion analysis of each HL subtype (Figure 6) show that $44 \%$ (15 of 34) of the participants have HL curves roughly flat at low frequencies and high steep at high frequencies; $32 \%$ (11 of 34) of the participants have more or less flat HLs. HLs are continuously steep for $15 \%$ (5 of 34) of participants. And, for the other $9 \%$ (3 of 34), HLs have a scotoma at $4-6 \mathrm{kHz}$.

Numerical proportional analysis applied to tinnitus laterality, tinnitus sound, and tinnitus etiology, of 23 subjects of HS, CS, and ST HL subtypes, affords the results depicted in Figure 7. Concerning the tinnitus laterality, Figure 7a, $43 \%$ of subjects (10 of 23) allocate their tinnitus to left ear, in $35 \%$ of subjects ( 8 of 23 ) the tinnitus is bilateral, $13 \%$ (3 of 23 ) perceive the tinnitus in the head (central), and only 2 of $23(8 \%)$ assign their tinnitus to the right ear. Notice that there are people with several types of tinnitus, allocated to distinct parts of the head. In these cases, tinnitus is assigned to the dominant (more intense) tinnitus. Regarding the tinnitus sound, Figure $7 \mathrm{~b}$, the more frequent is tonal $(39 \%$, 9 of 23 ), followed by ringing (35\%, 8 of 23$)$, and hissing $(26 \%, 6$ of 23$)$. As before, when subjects refer to several tinnitus sounds, the more prominent is assigned. Finally, the predominant tinnitus etiology (Figure 7c) was sensorineural HL (HL induced in Table 3$)$, with a percentage of $39 \%(9$ of 23$)$, followed by noise $(30 \%, 7$ of 23$)$, idiopathic $(13 \%$,

Figure 5: MATLAB GUI for tinnitus pitch matching.

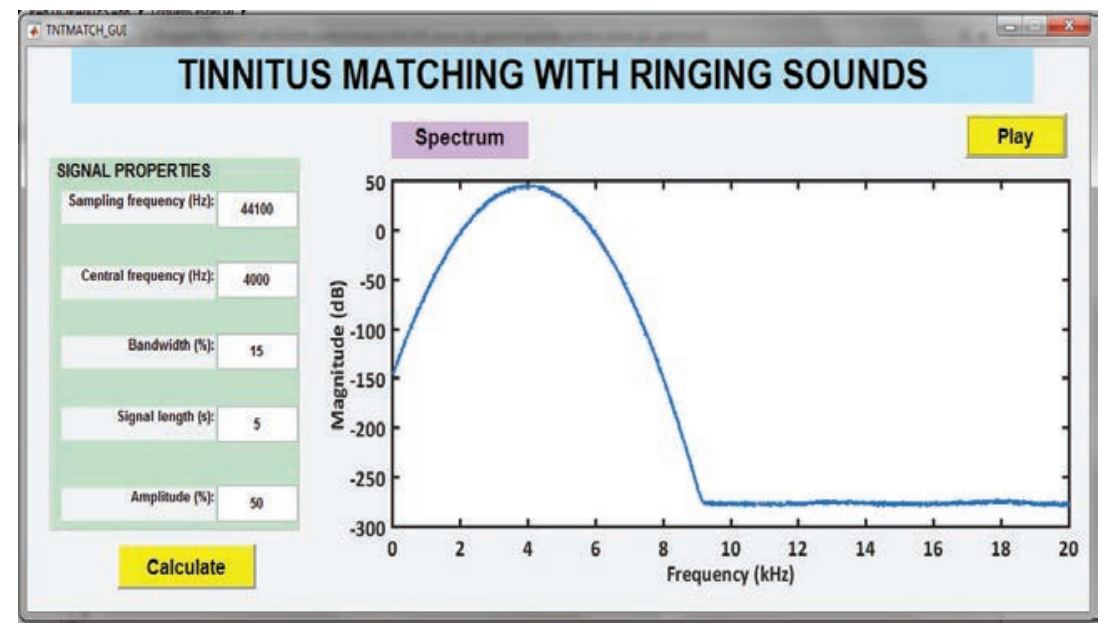


Table 3: Tinnitus features of participants.

\begin{tabular}{|c|c|c|c|c|c|c|c|c|c|c|}
\hline Subject & Sex & Age & $\begin{array}{c}\text { Tinnitus } \\
\text { duration } \\
\text { (years) }\end{array}$ & $\begin{array}{l}\text { Tinnitus } \\
\text { location }\end{array}$ & $\begin{array}{l}\text { Tinnitus } \\
\text { sound }\end{array}$ & $\begin{array}{c}\text { Tinnitus } \\
\text { pitch }(\mathrm{Hz})\end{array}$ & $\begin{array}{c}\text { Tinnitus } \\
\text { bandwidth } \\
\text { (\%) }\end{array}$ & THI & $V A S$ & Tinnitus Etiology \\
\hline 1 & $\mathrm{~F}$ & 45 & 0.7 & Bilateral & Ringing & 2200 & 1 & 60 & 75 & Idiopathic \\
\hline 2 & M & 63 & 10 & Bilateral & Hissing & 5000 & 30 & 4 & 30 & $\mathrm{HL}$ induced \\
\hline 3 & M & 39 & 2 & Left ear & Tonal & 6000 & & 16 & 55 & Idiopathic \\
\hline 4 & M & 44 & 2.8 & Central & Ringing & 4500 & 1 & 74 & 75 & HL induced \\
\hline 5 & M & 53 & 4 & Left ear & Ringing & 4400 & 4 & 10 & 15 & Stress. HL induced \\
\hline 6 & M & 50 & 7 & Left ear & Tonal & 12500 & & 20 & 25 & HL induced \\
\hline 7 & M & 43 & 3 & Left ear & Ringing & 7000 & 3 & 34 & 65 & Idiopathic \\
\hline 8 & $\mathrm{~F}$ & 50 & 10 & Bilateral & Tonal & 8000 & & 22 & 30 & Head trauma induced \\
\hline 9 & $\mathrm{~F}$ & 41 & 14 & Left ear & Tonal & 3000 & & 38 & 55 & HL induced \\
\hline \multirow[t]{2}{*}{10} & $\mathrm{~F}$ & 67 & 1 & Left ear & Tonal & 4000 & & 36 & 75 & Idiopathic etiology \\
\hline & & & & & Ringing & 6000 & 5 & & & \\
\hline 11 & M & 28 & 14 & Bilateral & Tonal & 9000 & & 42 & 60 & Head trauma induced \\
\hline 12 & M & 72 & 11 & Left ear & Tonal & 4000 & & 54 & 50 & Noise induced \\
\hline \multirow[t]{2}{*}{13} & $\mathrm{~F}$ & 45 & 8 & Bilateral & Tonal & 3800 & 1 & 64 & 70 & Idiopathic \\
\hline & & & & & Ringing & 250 & & & & \\
\hline 14 & M & 62 & 10 & Right ear & Ringing & 3100 & 1 & 18 & 65 & HL induced \\
\hline 15 & M & 31 & 0.3 & Bilateral & Hissing & 2400 & 17 & 88 & 85 & Noise induced \\
\hline 16 & M & 68 & 16 & Bilateral & Tonal & 8300 & & 30 & 75 & Stress. HL induced \\
\hline 17 & $\mathrm{~F}$ & 47 & 12 & Left ear & Tonal & 5200 & & 50 & 75 & Eustachian tube dysfunction \\
\hline \multirow[t]{2}{*}{18} & M & 65 & 20 & Bilateral & Ringing & 300 (RE) & 5 & 52 & 70 & Otitis. HL induced \\
\hline & & & & & & 7000(LE) & 7 & & & \\
\hline 19 & $\mathrm{~F}$ & 61 & 0.4 & Left ear & Hissing & 1000 & 25 & 14 & 25 & Noise induced \\
\hline 20 & M & 41 & 1 & Left ear & Ringing & 8000 & 1 & 50 & 60 & Idiopathic \\
\hline 21 & M & 47 & 8 & Right ear & Ringing & 12000 & 5 & 10 & 55 & Noise induced \\
\hline \multirow[t]{2}{*}{22} & $\mathrm{~F}$ & 45 & 0.3 & Central & Hissing & 100 & 60 & 56 & 55 & HL induced \\
\hline & & & & & & 2000 & 50 & & & \\
\hline \multirow[t]{2}{*}{23} & M & 42 & 0.1 & Left ear & Ringing & 7000 & 10 & 36 & 65 & Otitis \\
\hline & & & & & Tonal & 7000 & & & & \\
\hline 24 & M & 37 & 1.1 & Left ear & Ringing & 7000 & 2 & 26 & 30 & Eustachian tube dysfunction \\
\hline 25 & M & 69 & 0.8 & Left ear & Hissing & 3500 & 20 & 48 & 60 & Stress. Noise induced \\
\hline 26 & M & 44 & 1.3 & Left ear & Tonal & 8800 & & 62 & 70 & Stress. Idiopathic \\
\hline \multirow[t]{2}{*}{27} & $\mathrm{~F}$ & 26 & 0.17 & Central & Hissing & 1500 & 20 & 62 & 70 & Stress. Eustachian tube \\
\hline & & & & & Tonal & 8000 & & & & dysfunction \\
\hline 28 & $\mathrm{~F}$ & 29 & 0.25 & Bilateral & Hissing & 3000 & 20 & 96 & 75 & Stress. Acoustic trauma. \\
\hline 29 & M & 58 & 0.25 & Left ear & Tonal & 5500 & & 22 & 35 & HL induced \\
\hline \multirow[t]{3}{*}{30} & $\mathrm{~F}$ & 42 & 0.42 & Bilateral & Hissing & 125 (LE) & 20 & 32 & 55 & Stress. \\
\hline & & & & & Tonal & 4000 (RE) & & & & \\
\hline & & & & & & 9000 (RE) & & & & \\
\hline 31 & $\mathrm{~F}$ & 41 & 1.3 & Left ear & Hissing & 1000 & 40 & 70 & 70 & $\begin{array}{l}\text { Stress. Sinusitis. Eustachian } \\
\text { tube dysfunction }\end{array}$ \\
\hline \multirow[t]{2}{*}{32} & M & 36 & 0.33 & Left ear & Tonal & 3100 & & 50 (day) & 82 & Head trauma. Noise \\
\hline & & & & & & & & 80(night) & & induced \\
\hline \multirow[t]{2}{*}{33} & M & 75 & 0.25 & Central & Hissing & 4000 & 30 & 80 & 84 & Noise induced \\
\hline & & & & & Tonal & 3500 & & & & \\
\hline 34 & $\mathrm{~F}$ & 50 & 1.5 & Bilateral & Tonal & 7500 & & 65 & 76 & HL induced \\
\hline
\end{tabular}


3 of 23 ), conductive HL ( $9 \%, 2$ of 23$)$, and head trauma $(9 \%, 2$ of 23$)$. Notice that stress (see Table 3$)$ was considered a comorbid effect and not a triggering cause of tinnitus.

Table 2 summarizes the mean F20, F50, and Fmax for the participants with HS, CS, and ST subtypes, together with the corresponding tinnitus pitches. For subjects with

Figure 6: HL curves subtypes.

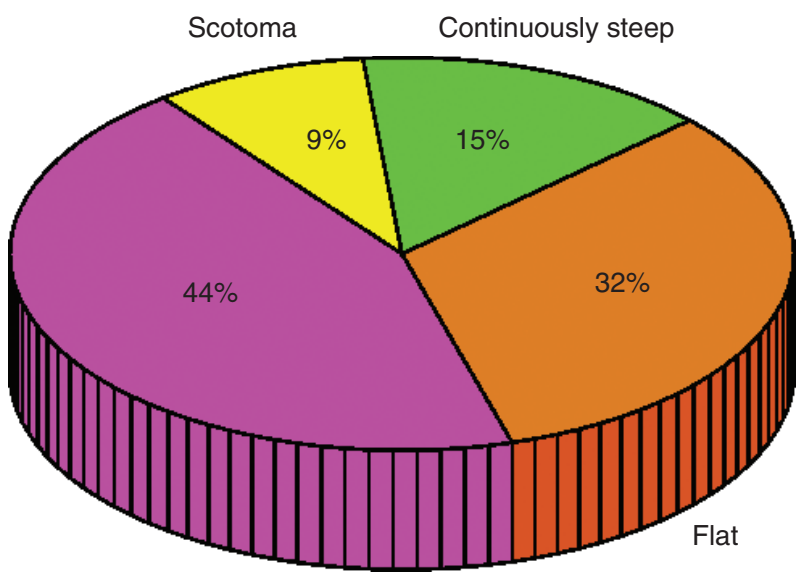

High-steep high-frequency unilateral tinnitus, the F20, F50, and Fmax values of the corresponding ear are chosen. For subjects with either bilateral or central tinnitus, the mean of left and right ears is selected.

Figure 8 shows the mean differences between TP and F20, TP and F50, and TP and Fmax. For HS HF and CS HL subtypes, it can be seen that F20 underestimates, Fmax overestimates, and F50 is the closest estimator of the TP. For ST HL subtype, the three variables underestimate the tinnitus pitch. Figure 9 shows the average HL curves for the three HL subtypes with the values of F20, F50, Fmax, and TP superimposed.

Figures 10-12 show scatter plots for F20 versus TP, F50 versus TP, and Fmax versus TP, for the three HL subtypes, respectively. Again, for the HS and CS subtypes, it can be seen that F20 underestimates TP, Fmax overestimates TP, and F50 is the best estimator of TP. For HL curves with scotoma, neither F20, F50 nor Fmax approach sufficiently to TP. However, taking into account that ST subgroup has only three participants, this assertion does not have enough statistical power. Since scatter results are similar for HS and CS HL subtypes, we could integrate both in just a subgroup. Figure 13 shows a joint scatter plot for both subtypes. Table 4 summarizes the $\rho$ and $p$ values obtained when applying Spearman rank correlation to the paired variables F20-TP, F50-TP, and Fmax-TP for the join HS

Figure 7: (a) Tinnitus laterality, (b) Tinnitus sound, and (c) Tinnitus etiology.

(a)

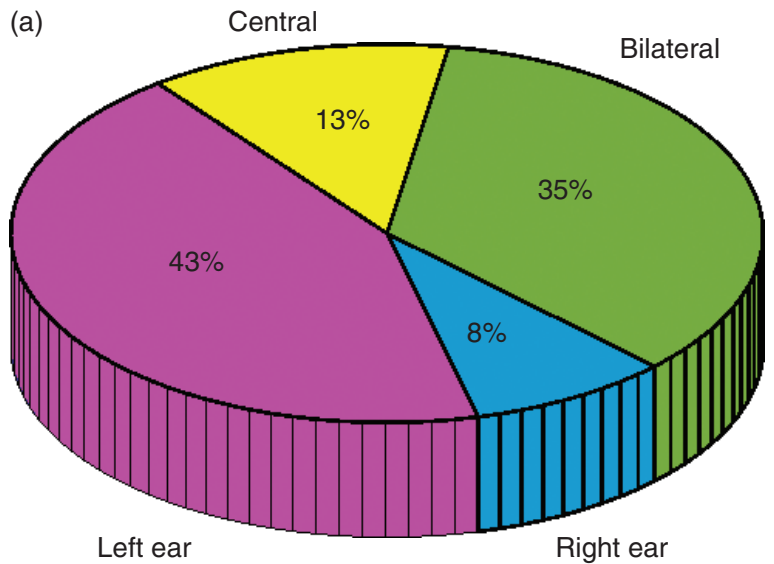

(b)

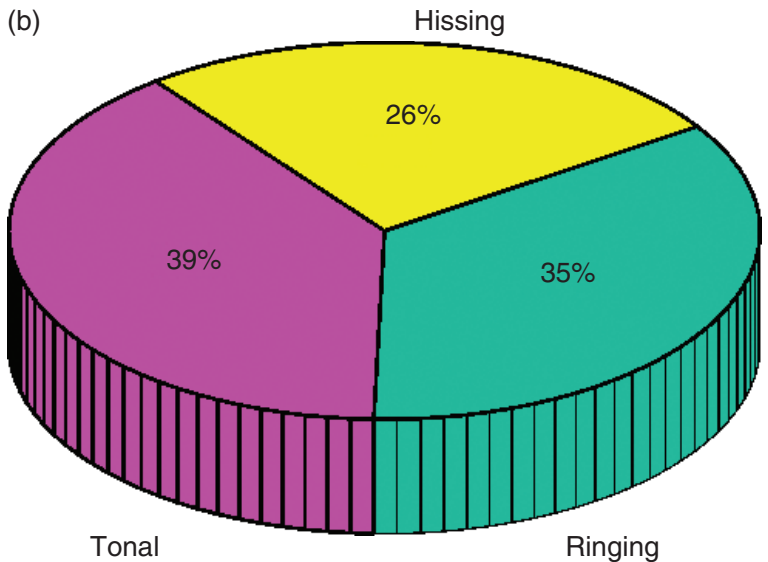

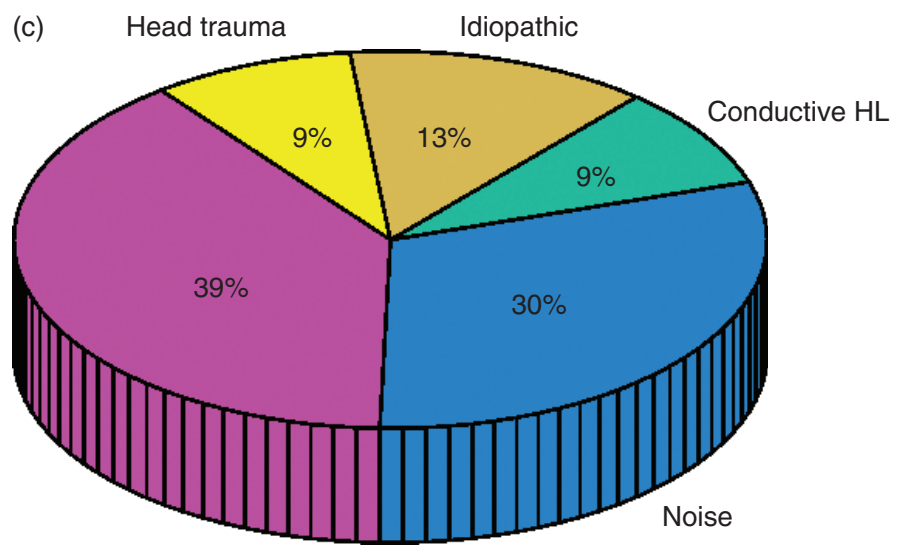

sensorlneural HL 
Figure 8: Mean differences between TP and F20, F50 and Fmax for (a) high-steep high-frequency HL subtype, (b) continuously steep HL subtype, and (c) HL with scotoma subtype.

(a) HS HF

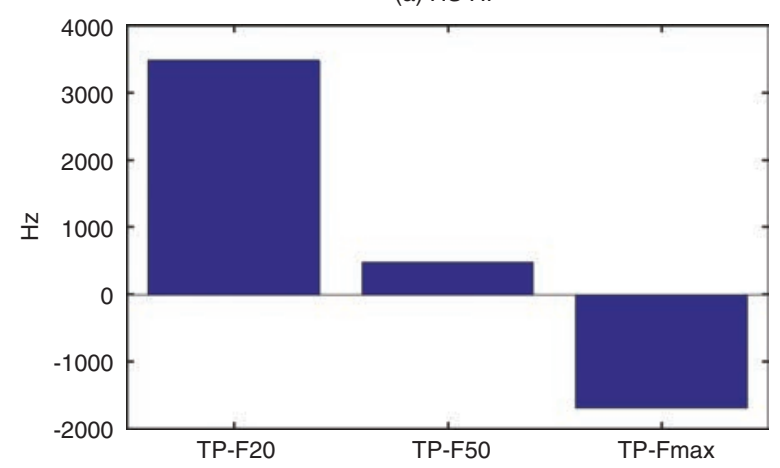

(b) CS

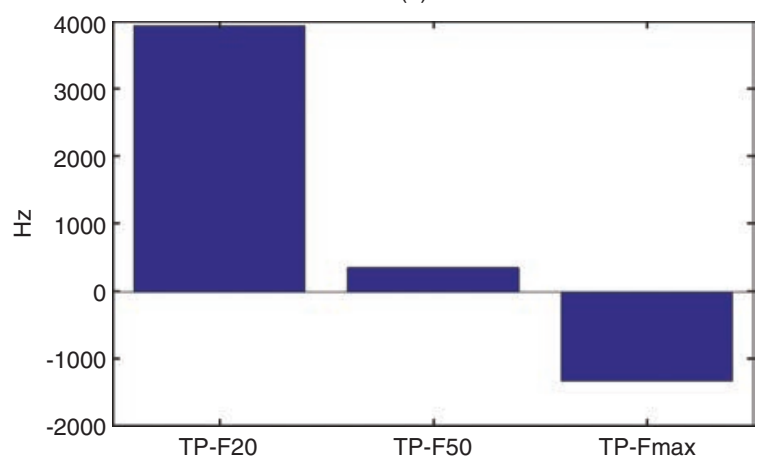

(c) ST

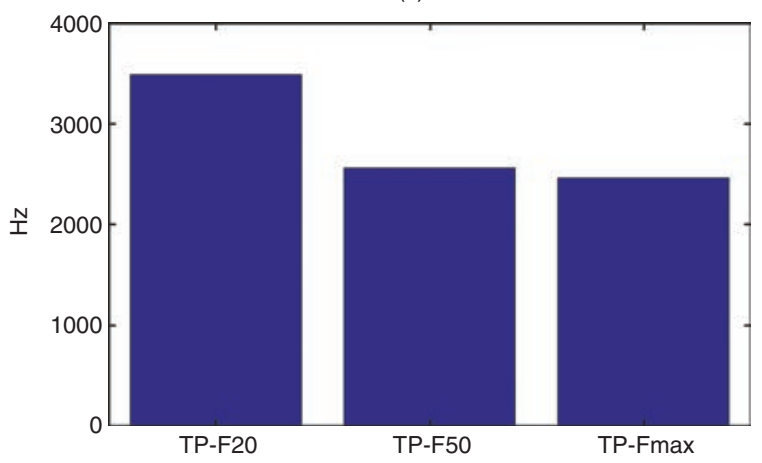

Figure 9: Mean HL curves for the three subtypes, with the values of F20, F50, Fmax, and TP overimposed.
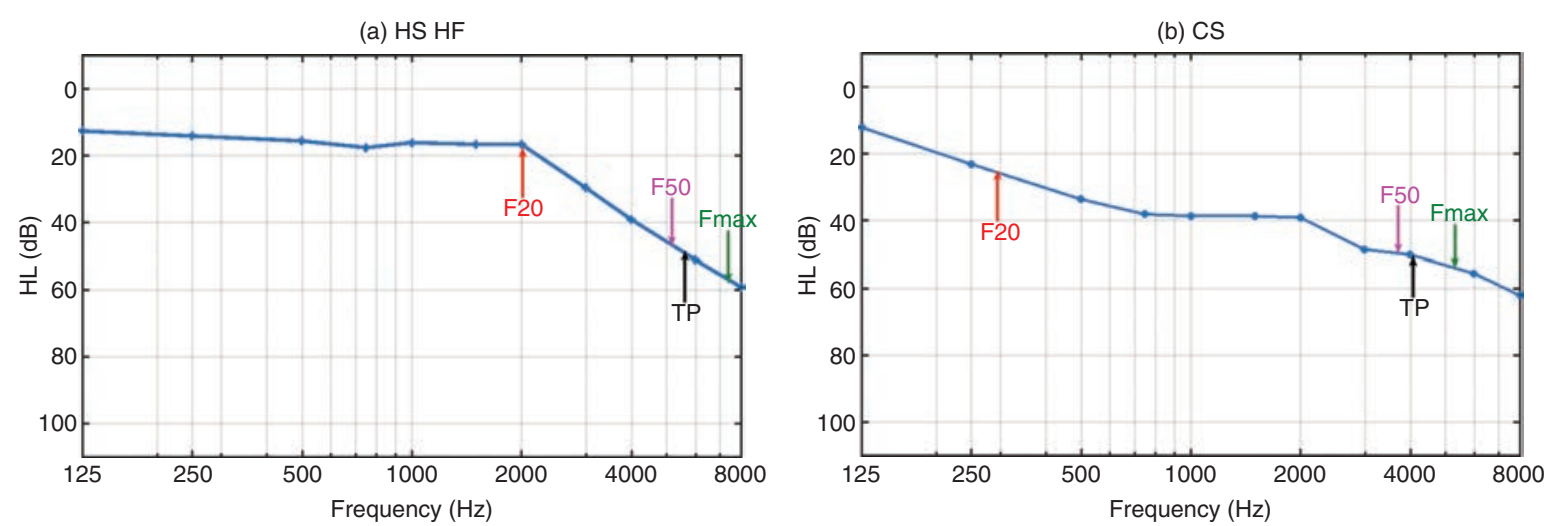

(c) ST

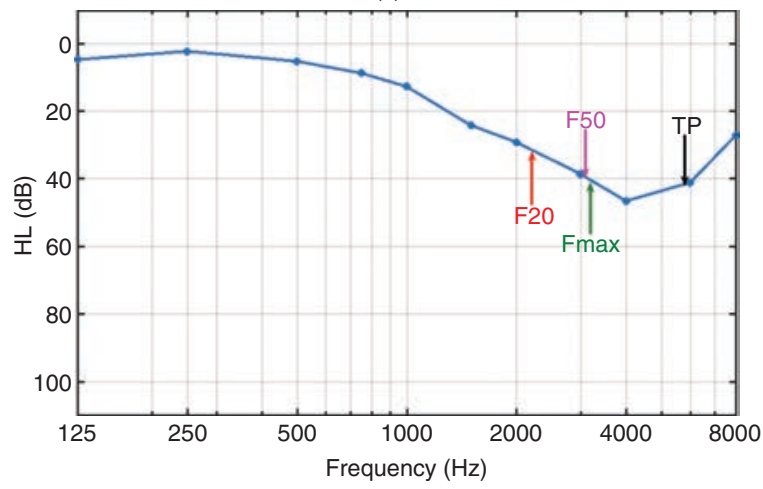


Figure 10: Scatter plot of (a) F20 versus TP, (b) F50 versus TP, and (c) Fmax versus TP, for high-steep high-frequency HL subtype.
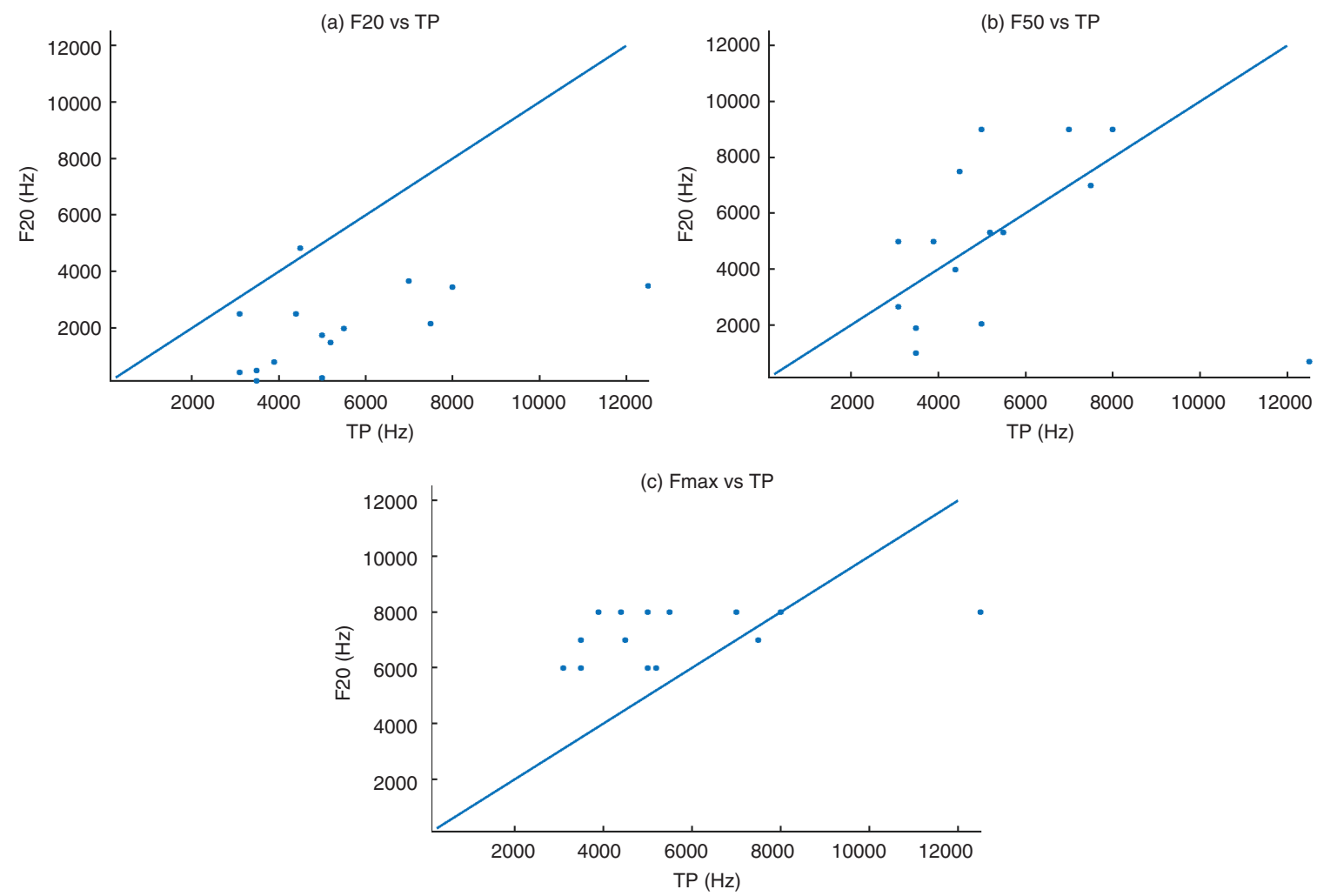

Figure 11: Scatter plot of (a) F20 versus TP, (b) F50 versus TP, and (c) Fmax versus TP, for continuously steep HL subtype.

(a) F20 vs TP

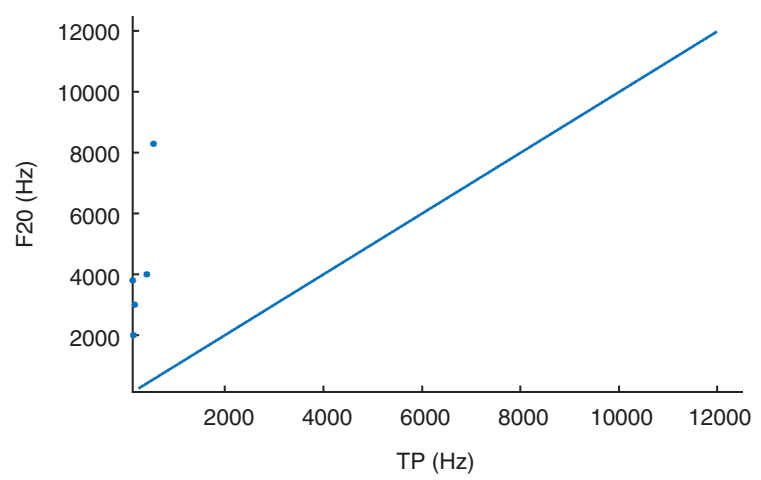

(b) F50 vs TP

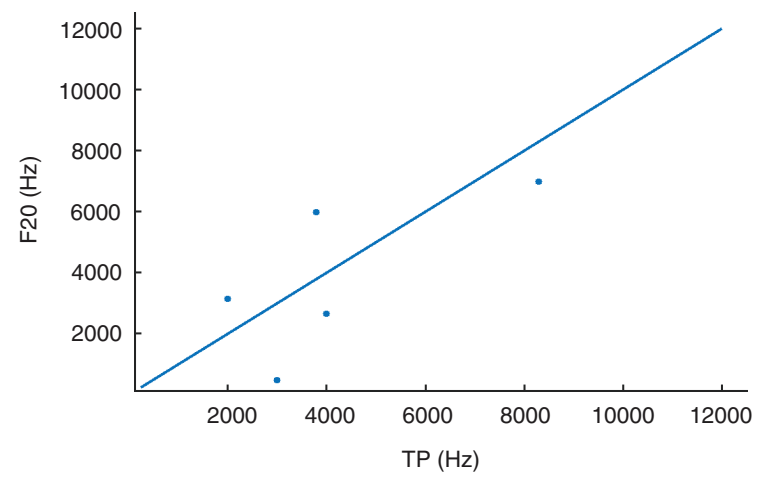

(c) Fmax vs TP

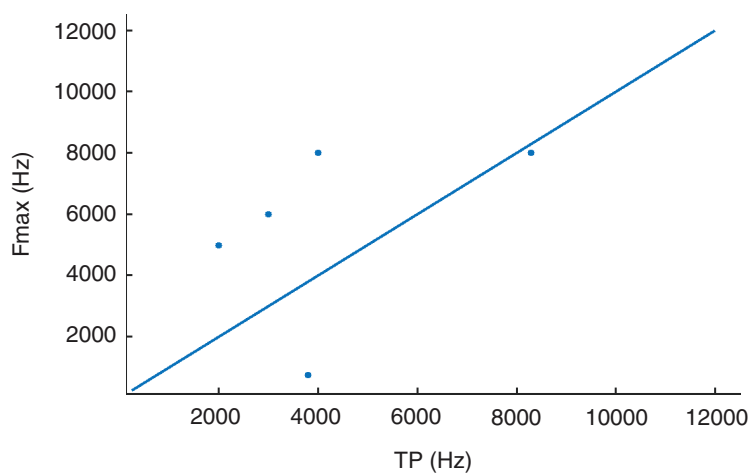


Figure 12: Scatter plot of (a) F20 versus TP, (b) F50 versus TP, and (c) Fmax versus TP, for HL with scotoma subtype.

(a) F20 vs TP

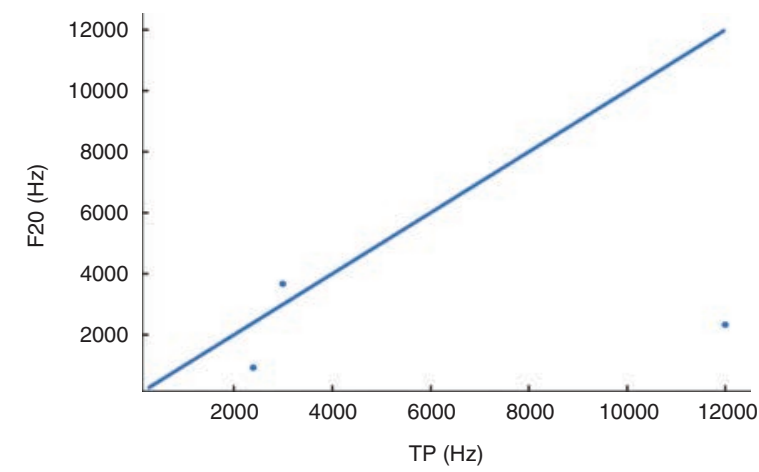

(b) F50 vs TP

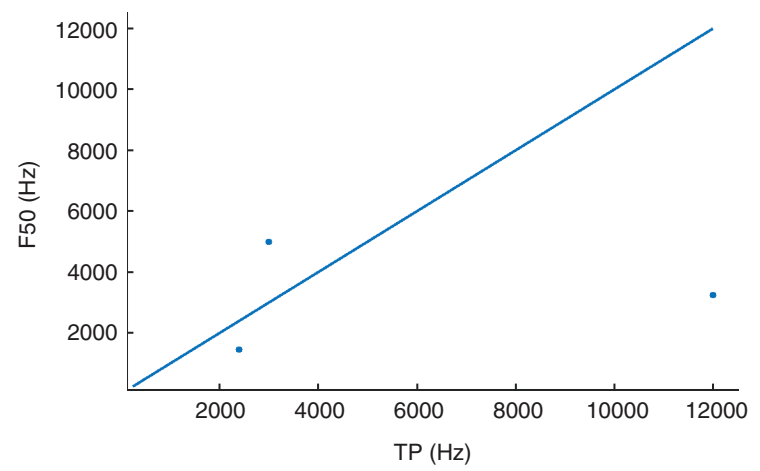

(c) Fmax vs TP

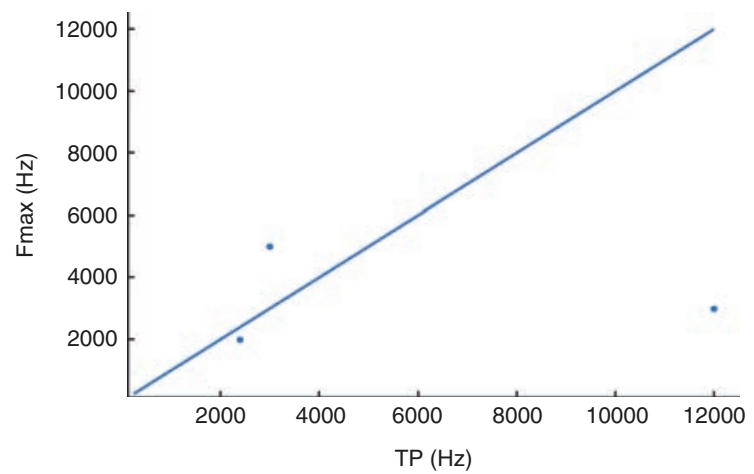

Figure 13: Scatter plot of (a) F20 versus TP, (b) F50 versus TP, and (c) Fmax versus TP, for high steep high-frequency (blue) and continuously steep (red) HL subtypes.

(a) F20 vs TP

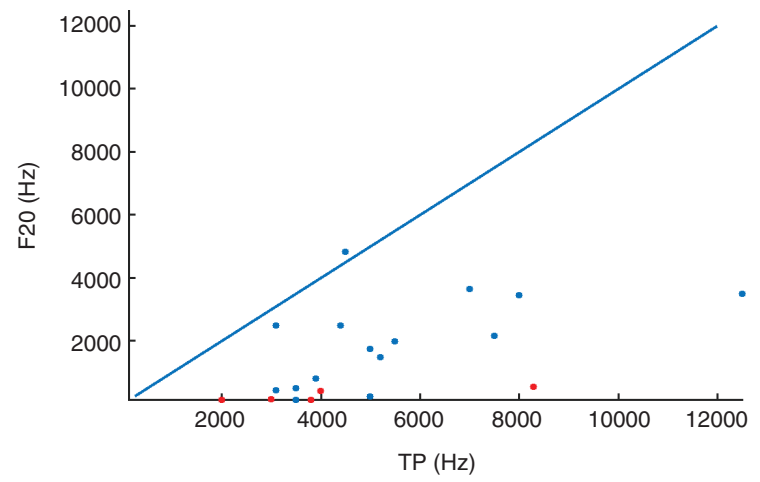

(b) F50 vs TP

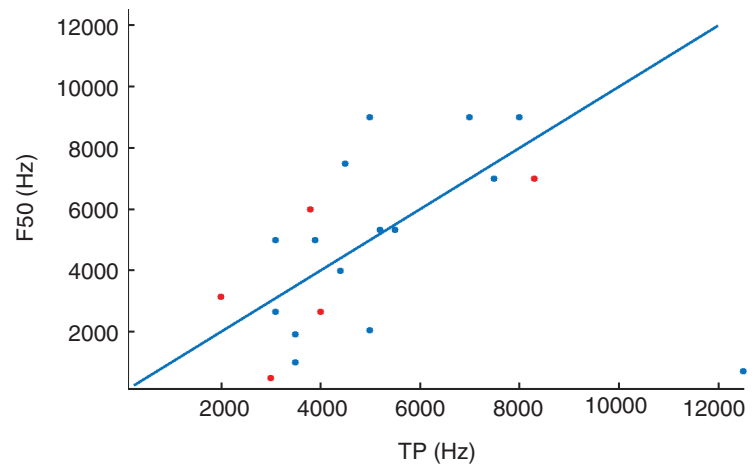

(c) Fmax vs TP

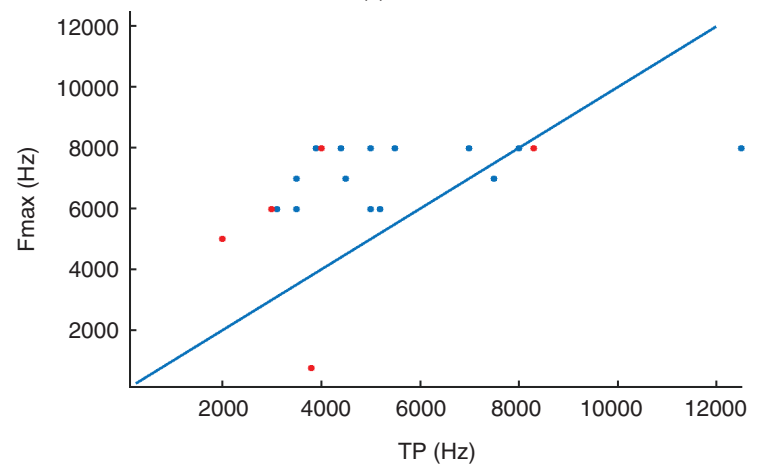


Table 4: Spearman rank correlation analysis between paired audiometric-tinnitus variables for the subjects with HS and CS HL subtypes.

\begin{tabular}{lcc}
\hline Paired variables & $\boldsymbol{r}$ & $\boldsymbol{p}$ \\
\hline F20 versus TP & 0.59 & 0.006 \\
F50 versus TP & 0.49 & 0.027 \\
Fmax versus TP & 0.65 & 0.002 \\
\hline
\end{tabular}

and CS HL subgroup. As it can be seen, there exists a positive correlation between audiometric (moderate for F20 and F50 and strong for Fmax) and tinnitus (TP) features.

\section{DISCUSSION}

Our categorization of HL subtypes (Figure 6) is slightly different to that of Nicolas-Puel et al. (2002). In a similar way to them, we consider high-steep high-frequency and flat HL subtypes. However, the other two subtypes, namely, continuously steep and scotoma HL, could differ of the low-frequency HL and dead ear considered by Nicolas-Puel et al. König et al. (2006) and Shekhawat et al. (2014) only considered tinnitus subjects with high-steep high-frequency HL and continuously steep HL, respectively. Serena et al. (2011), on the other hand, distinguished between 0-break "broken-stick" HL (similar to our flat HL), 1-break "broken-stick" (similar to our HS HL), and 2-break "broken-stick", without matching to our subgroups. Langguth et al. (2017) defined four HL subgroups; namely (1) normal hearing (0-20 dB HL); (2) mild/moderate HL (25-50 dB HL), representing mostly outer hair cell loss; (3) severe/profound HL (>50 dB HL), representing outer and inner hair cell damage; and (4) no data available.

The most prevalent HL subtype in our cohort is highsteep high-frequency HL (44\%), followed by flat HL $(32 \%)$, continuously steep HL $(15 \%)$ and scotoma HL ( $9 \%$ ). If HS and CS would be included in a joint subtype, then the prevalence of both should be $59 \%$. Regarding the flat HL curves, it might be emphasized that we have measured just up to $8 \mathrm{kHz}$. Therefore, HL flat up to $8 \mathrm{kHz}$ does not exclude the occurrence of losses above $8 \mathrm{kHz}$ which can potentially trigger tinnitus, mainly at high frequencies (Weisz et al., 2006). High frequency losses (8-16 kHz) have been recently interpreted as an early indication of cochlear synaptopathy in humans (Milloy et al., 2017). Cochlear synaptopathy, also named hidden HL, is the selective loss of synaptic connections between highthreshold and low-spontaneous rate IHCs with the auditory nerve, showing or not threshold elevations, due to the loss of hair cells-auditory nerve synaptic connection (Liberman \& Liberman, 2015). The loss of these connections can reach $40-50 \%$ without elevating hearing thresholds. As HL is considered the most likely trigger of tinnitus, this subgroup is further excluded of the correlational analysis between audiometric and tinnitus features.

Concerning the tinnitus lateralization (Figure 7a), surprisingly $43 \%$ of subjects with $\mathrm{HS}, \mathrm{CS}$, or ST HL perceived their tinnitus in the left ear, in contrast to subjects perceiving their tinnitus in the right ear, only $8 \%$. In the cohort of Scheklmann et al. (2012) there was also a bias toward the left ear ( 72 versus 45 subjects). In the cohort of Shekhawat et al. (2014), on the contrary, 103 participants had the predominant tinnitus towards the right ear, versus 83 subjects with their tinnitus towards the left ear. Therefore, the high bias of the unilateral tinnitus towards the left ear in our cohort might be considered merely casual.

The tinnitus sound of our sample differs also from other databases. In our cohort (Figure $7 \mathrm{~b}$ ), pure tone and ringing have a similar prevalence $(39 \%$ and $35 \%$, respectively), while hissing is less prevalent $(26 \%)$. In the Tinnitus Archive of the Oregon Health State University (OHSU), tonal, ringing, and hissing are also the more frequent tinnitus sounds, but with a different prevalence. When more than one predominant sound is reported, ringing is prominently the more prevalent sound.

Notice also that, when flat HL subtype is excluded, sensorineural $\mathrm{HL}$ is the most possible origin of tinnitus referred by participants (39\%), followed by noise (30\%) (Figure 7c).

Our results concur with those of Shekhawat et al. (2014) regarding the audiometric feature which correlates better with the tinnitus pitch (Figures 8 and 9), at least for the HS and CS HL subtypes. In effect, our results confirm that F20 (the frequency at which audiometry crosses $\mathrm{HL}=20 \mathrm{~dB}$ ) and Fmax (the frequency at which HL is maximum) under- and overestimate, respectively, the tinnitus pitch. Spearman rank correlation analysis confirms that tinnitus pitch increases monotonically with F20, F50, and Fmax (Figures 10-12 and Table 4), but that it is better correlated with F50. This corroborates the hypothesis that tinnitus pitch is matched to the frequency at which hearing loss reaches $50 \mathrm{~dB}$ HL (Shekhawat et al., 2014).

\section{CONCLUSIONS}

This article contains a preliminary correlational study between audiometric characteristics and tinnitus features in a sample of 34 human subjects with tinnitus. Following the current trend of tinnitus heterogeneity, subjects are categorized first in four subgroups, taking into account the shape of HL curves, namely flat HL, high-steep highfrequency HL, continuously steep HL, and HL with scotoma. The more prevalent subgroup was the high-steep high-frequency HL. Excluding the flat HL subgroup, three audiometric features are calculated from the HL curves: F20, the frequency at which $\mathrm{HL}=20 \mathrm{~dB}, \mathrm{~F} 50$, the frequency at which $\mathrm{HL}=50 \mathrm{~dB}$, and Fmax, the frequency at which $\mathrm{HL}$ is maximum.

Tinnitus characteristics include tinnitus laterality (left ear, right ear, bilateral, or central), tinnitus sound (tonal, ringing, or hissing), tinnitus etiology, THI, VAS, and tinnitus pitch (TP). Tinnitus laterality, sound, and etiology were evaluated by the responses of participants to an interview. TP was assessed by matching the tinnitus of participants to a band-filtered noise generated by a GUI. 
Depending on the bandwidth of the filter, tones (very narrow), ringing (narrow), or hissing (wide) sounds were generated.

Correlational studies included paired audiometrictinnitus variables analysis. Spearman rank correlation analysis confirmed that TP increases monotonically with the three audiometric variables. Mean variables, TP-F20, TP-F50, and TP-Fmax were also analyzed. Results demonstrated that F20 understimates TP, Fmax overstimates $\mathrm{TP}$, and F50 is the best estimator of TP. Therefore, our results confirm that F50, the frequency at which IHC damage begins, is likely the best predictor of the associated tinnitus pitch.

\section{ACKNOWLEDGMENTS}

The enthusiastic participation of volunteers in this study is kindly recognized. Financial support was provided by CSIC through grant 201750E037.

\section{REFERENCES}

Cobo, P. (2015). Tinnitus: Mechanisms, measures and sound treatments. Loquens, 2, e024. https://doi.org/10.3989/ loquens.2015.024

Diges, I., Simón, F., \& Cobo, P. (2017). Assessing auditory processing deficits in tinnitus and hearing impaired patients with the Auditory Behavior Questionnaire. Frontiers in Neuroscience, 11, 187. https://doi.org/10.3389/ fnins.2017.00187

Eggermont, J. J. (2012). The neuroscience of tinnitus. Oxford: Oxford University Press. https://doi.org/10.1093/acprof: oso/9780199605606.001.0001

Eggermont, J. J. (2014). Noise and the brain. Amsterdam: Elsevier. https://doi.org/10.1016/B978-0-12-415994-5.00011-7

Eggermont, J. J., \& Tass, P. A. (2015). Maladaptive neural synchrony in tinnitus: Origin and restoration. Frontiers in Neurology, 6, 29. https://doi.org/10.3389/fneur.2015.00029

Hall, D. A., Haider, H. Kikidis, D., Mielczarek, M., Mazurek, B., Szczepek, A. J., \& Cederroth, C. R. (2015). Toward a global consensus on outcome measures for clinical trials in tinnitus. Trends in Amplification, 19, 1-7. https://doi. org/10.1177/2331216515580272

Herráiz, C., Hernández Calvín, F. J., Plaza, G., Tapia, M. C., \& de los Santos, G. (2001). Evaluación de la incapacidad en los pacientes con acúfenos. Acta Otorrinolaringológica Española, 52, 142-145. https://doi.org/10.1016/ S0001-6519(01)78247-7

Kleinjung, T., Steffens, T., Struz, J., \& Langguth, B. (2009). Curing tinnitus with a Cochlear Implant in a patient with unilateral sudden deafness: A case report. Cases Journal, 2, 7462. https://doi.org/10.1186/1757-1626-2-7462

König, O., Schaette, R., Kempter, R., \& Gross, M. (2006). Course of hearing loss and occurrence of tinnitus.
Hearing Research, 221, 59-64. https://doi.org/10.1016/j. heares.2006.07.007

Langguth, B., Landgrebe, M., Schlee, W., Schecklmann, M., Vielsmeier, V., Steffens, T., Staudinger, S., Frick, H., \& Frick, U. (2017). Different Patterns of hearing loss among Tinnitus Patients: a latent class analysis of a large sample. Frontiers in Neuroscience, 8, 46. https://doi.org/10.3389/ fneur.2017.00046

Liberman, L. D., \& Liberman, C. M. (2015). Dynamics of cochlear synaptopathy after acoustic overexposure. Journal of the Association Research of Otolaryngology, 16, 205-219. https://doi.org/10.1007/s10162-015-0510-3

Milloy, V., Fournier, P., Benoit, D., Noreña, A., \& Koravand, A. (2017). Auditory brainstem responses in tinnitus: A review of who, how, and what? Frontiers in Aging Neuroscience, 9, 237. https://doi.org/10.3389/fnagi.2017.00237

Nicolas-Puel, C., Lloyd Faulconhridge, R., Guitton, M., Puel, J. L., Mondain, M., \& Uziel, A. (2002). Characteristics of tinnitus and etiology of associated hearing loss: A study of 123 patients. International Tinnitus Journal, 8, 37-44.

Noreña, A. J. (2011). An integrative model of tinnitus based on a central gain controlling neural sensitivity. Neuroscience and Biobehavioral Reviews, 35, 1089-1109. https://doi. org/10.1016/j.neubiorev.2010.11.003

Roberts, L. E., Bosnyak, D. J., Bruce, I. C., Gander, P. E., \& Paul, B. T. (2015). Evidence for differential modulation of primary and nonprimary auditory cortex by forward masking in tinnitus. Hearing Research, 327, 9-27. https:// doi.org/10.1016/j.heares.2015.04.011

Roberts, L. E., Moffat, G., \& Bosnyak, D. J. (2006). Residual inhibition functions in relation to tinnitus spectra and auditory threshold shift. Acta Otolaryngol. (Stockh), 126, 27-33. https://doi.org/10.1080/03655230600895358

Schecklmann, M., Vielsmeier, V., Steffens, T., Landgrebe, M., Langguth, B., \& Kleinjung, T., (2012). Relationship between audiometric slope and tinnitus pitch in tinnitus patients: Insights into the mechanisms of tinnitus generation. PLOS One, 7, e34878. https://doi.org/10.1371/journal.pone.0034878

Sereda, M., Hall, D. H., Bosnyak, D. J., Edmondson-Jones, M., Roberts, L. E., Adjamian, P., \& Palmer, A. R. (2011). Re-examining the relationship between audiometric profile and tinnitus pitch. International Journal of Audiology, 50, 303-312. https://doi.org/10.3109/14992027.2010.551221

Shekhawat, G. S., Searchfield, G. D., \& Stinear, C. M. (2014). The relationship between tinnitus pitch and hearing sensitivity. Eur. Arch. Otolaryngol., 271, 41-48. https://doi. org/10.1007/s00405-013-2375-6

Van de Heyning, P., Meeus, O., Blaivie, C., Vermeire, K., Boudewyns, A., \& De Ridder, D. (2007). Tinnitus: a multidisciplinary clinical approach. B-ENT 3, 3-10.

Vio, M. M., \& Holme, R. H. (2005). Hearing loss and tinnitus: 250 million people and US\$10 billion potential market. Drugs Discovery Today, 10, 1263-1265. https://doi. org/10.1016/S1359-6446(05)03594-4

Weisz, N., Hartmann, T., Dohrmann, K., Schlee, W., \& Noreña, A. (2006). High-frequency tinnitus without hearing loss does not mean absence of deafferentation. Hearing Research, 222, 108-114. https://doi.org/10.1016/j. heares.2006.09.003 